\title{
Perspectivas para una Bioética latinoamericana
}

\author{
Andrés Peralta Cornielle
}

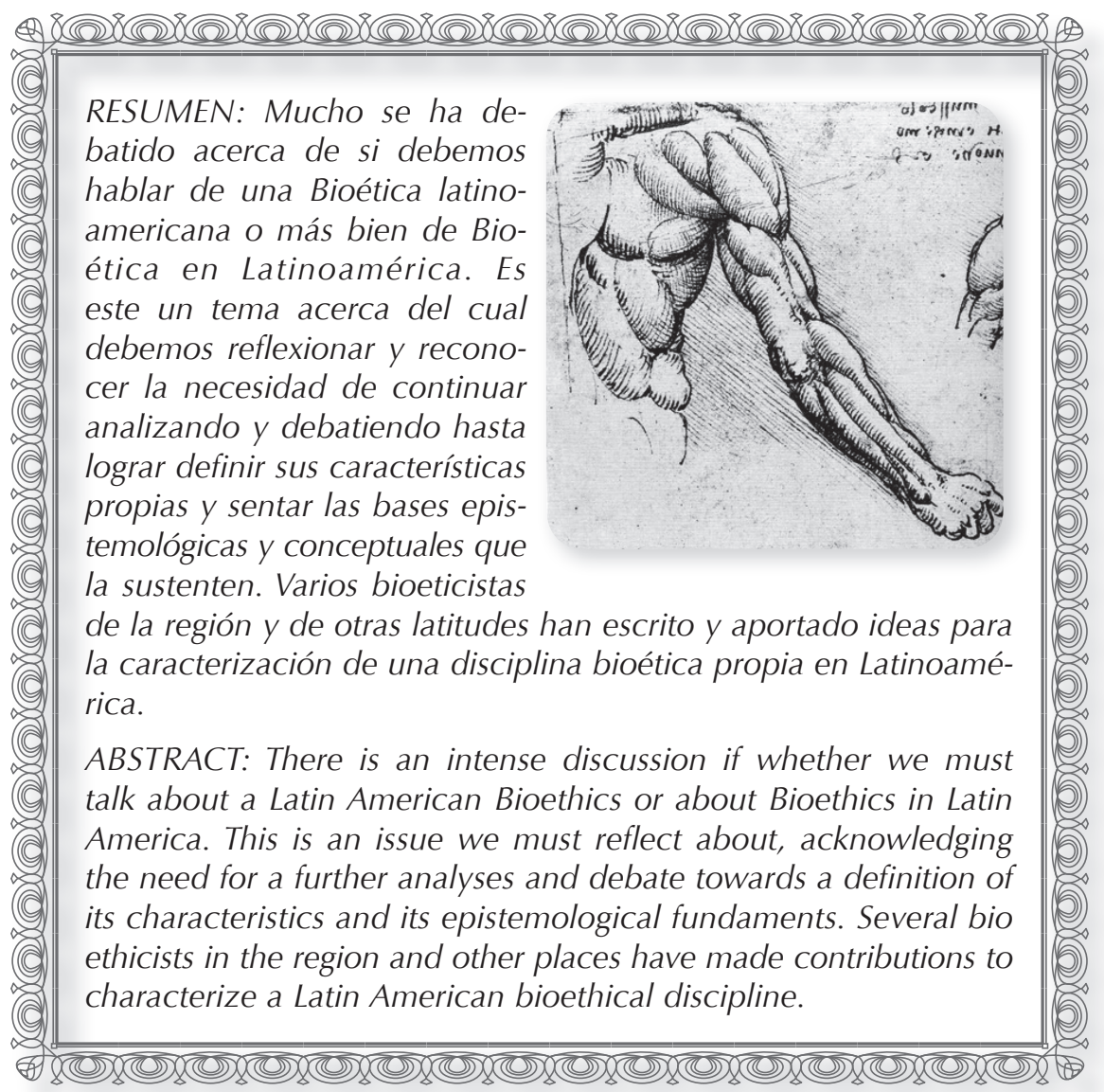




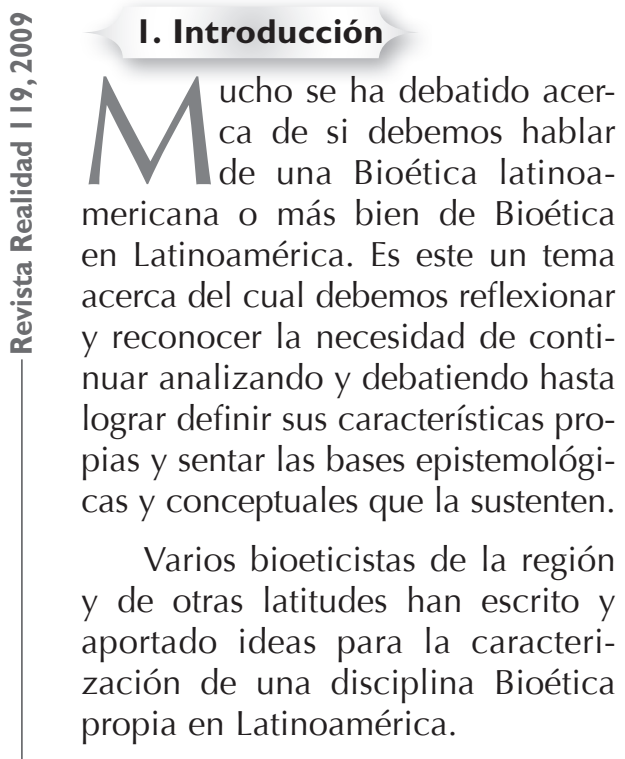

James Drane, al plantear sus propuestas para los fundamentos y desarrollo de la Bioética en nuestra región, se preguntó: “¿Qué hago yo aquí?", y se respondió: "Pretendo hablar de lo que ocurrió en mi país con el desarrollo de la Bioética, para que ustedes traten de evitar los errores que hemos cometido y desarrollen su propia Bioética. Los beneficios generados por el continuo desarrollo científico y tecnológico van también apareados con nuevos y más complejos problemas, que van generando cambios en las características y definiciones de la familia, de la cultura y de la sociedad. ¿Qué hacer en América Latina? Pueden importar modelos o dejarse influenciar por la profusión variada y creciente de la literatura de otros contextos culturales, socioeconómicos e históricos, y esto sería fatal. Lo que hace falta son estímulos para desarrollar una perspectiva Latinoamericana de la Bioética".

\section{Desafíos para una Bioética latinoamericana}

T omaré como aproximación de un marco referencial para una Bioética latinoamericana las opiniones de Fernando Lolas, de Chile, Juan C. Salas, de Colombia, J. A. Mainetti de Argentina, y H. Gros Espiel, de Uruguay.

Al plantear los temas y desafíos para una Bioética en Latinoamérica, Fernando Lolas nos indica: "Todo panorama de una realidad plural y compleja es necesariamente incompleto y está sesgado por los intereses de quienes lo formulan (...) Las reflexiones sobre los desafíos y temas para una Bioética Latinoa- mericana y los conceptos relativos a la institucionalización, fáctica o planificada, de los temas bioéticos en el contexto político, legislativo, social y académico, (al) examinar la evolución de la temática en los últimos veinte años, puede concordarse con el diagnóstico que publicaran Drane y Fuenzalida, en 1991, y comprobar (...)una importante expansión del interés público, del número de personas interesadas y de instituciones".

Más adelante, Lolas agrega: "Sin duda alguna, las características culturales e institucionales de 


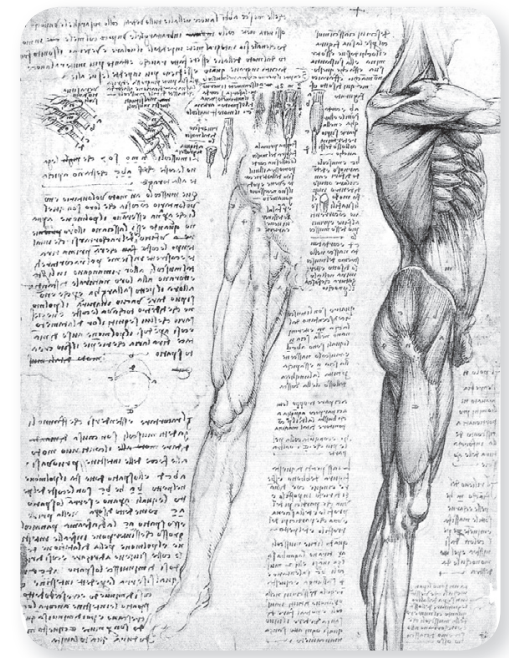

los países latinoamericanos hacen que muchos temas sean tratados de forma especial. Así, por ejemplo, la relación entre la fe religiosa y los grandes debates éticos que afectan a las personas y los grupos adquieren en el continente una particular tensión. La asimilación, a veces incompleta, de prácticas extranjeras bajo la forma de rituales administrativos hace que se confunda evaluación ética con manifestación de consignas o creencias, y de ese modo se retrasa el carácter reflexivo que debiera tener la empresa Bioética. La legislación del continente recoge ecos de otras tradiciones y sin duda contribuye al progreso de la alfabetización bioetica de las poblaciones pero también debe reconocerse que en los temas complejos desde el punto de vista científico no siempre es adecuada u oportuna" (1).

La fundamentación del concepto de la vida humana no está condicionada a factores geográficos o culturales, pero el desarrollo de los grupos sociales surge desde la unidad radical con la tierra, con la idiosincrasia y con la cultura, en una perspectiva de arraigo total con el contexto. Hace varias décadas se pensaba que América Latina, por la biodiversidad de sus riquezas naturales y por la convivencia pacífica y armónica de etnias multiculturales, podría convertirse en un importante foco de desarrollo mundial en el siglo XXI. Lamentablemente, entrado el nuevo siglo, los contrastes de opulencia y miseria, riqueza humana y natural y necesidades extremas de grandes grupos poblacionales, exuberantes bellezas naturales y la violencia desenfrenada, la calidad humana frente a los atentados en contra de los derechos humanos, no ofrecen un ambiente adecuado para buscar la unidad entre nuestros pueblos y "en donde la Bioética debe tener una palabra de aliento, de orientación, de vinculación, de esperanza y sobre todo de profundo compromiso con la vida humana en su entorno natural".

Juan Salas ha considerado que la construcción de una Bioética latinoamericana debe radicar en los siguientes aspectos: i) Una Bioética que esté determinada por lo que nos es propio axiológicamente: matices culturales, biodiversidad y riqueza etnica; ii) jerarquización de los problemas más urgentes que afectan las grandes masas poblacionales, como la pobreza, la violencia, la desnutrición, las enfermedades infecto-contagiosas, 
la vulnerabilidad y la inequidad social; iii) clara conciencia de las especificidades de la modalidad de los problemas generados por la marginación y el subdesarrollo; y iv) énfasis en las dinámicas de divulgación del carácter pedagógico de la Bioética, frente a la ignorancia de grandes sectores de población, que genera un ambiente propicio para la manifestación de los problemas contra la vida, tanto en los medios políticos, jurídicos, administrativos, como en los núcleos empresariales, periodísticos, educativos, familiares, etc. (2).

En opinión de J. A. Mainetti, la Bioética, como disciplina en el ámbito latinoamericano, además de ser la expresión de una ética de la vida, es la ética de la cultura vital, en la cual los principios de bienestar, libertad y justicia son predominantes, encarnando además un modelo de ética institucionalizada. De acuerdo a Mainetti, la Bioética en América Latina y el Caribe ha pasado por periodos de recepción (1985-1990), asimilación (1990-1995), recreación o creación (1995- ), y recomienda algunos criterios para caracterizar esa Bioética: i) Es más global que la anglosajona y quizás más ambiciosa; ii) es médico-filosófica; iii) es sanitaria y de tradición humanística; iv) tiene una proyección mas política, social y sanitaria que clínica; y vi) está fundamentada en tradiciones en un proceso de personalización social y político más amplio que el ámbito clínico.
"Sentimos como nunca la necesidad de reelaborar un modelo de ética que incluya la perspectiva comunitaria y que se oriente a la búsqueda del bien común (...) Tenemos la esperanza de contribuir con aspectos que enriquezcan el modelo bioético que ha prevalecido, aquellos que provinieron de una propuesta de la humanización de la medicina y que se inclinan hacia un modelo filosófico concreto. No creemos que basten inyecciones de fuertes dosis de ética para curar los males que sufre hoy la medicina, y menos pensamos que la ética puede reducirse a un conjunto de recetas. En este cambio la ética es muy importante, por cuanto prevé la dimensión prescriptiva derivada de los valores en juego y, sobre todo, debe ubicarse en los problemas del hombre y del conocimiento. Es tarea de aquellos que hunden sus raíces en la gran tradición humanística de occidente, no perder de vista el conjunto, de este cuadro teórico" (3).

Hace una década H. Gros Espiel planteó que nuestros países en vías de desarrollo habían tomado conciencia, en los intelectuales y en la opinión pública, de la importancia determinante de la Bioética y de la necesidad de no quedar marginada del progreso científico y tecnológico; de no ser un mero receptor, sino ser actor de este progreso y aplicarlo al mejoramiento humano integral. Nos advierte que la ignorancia humana y la incertidumbre de su futuro pueden ser 
terribles para el desarrollo normal de la vida y la transformación del hombre en un ser distinto, en algunos de sus elementos vitales del que hasta ahora ha sido, por lo cual hay que luchar por la afirmación del principio inmutable e invariable de la dignidad humana, invitándonos a recordar que "pese a todos los avances científicos (...), sabemos que lo que no sabemos es mas importante que lo que sabemos, que la única certidumbre es que ignoramos mucho y que, como ha dicho Jean Dusset, 'Si tengo una certidumbre es que toda ignorancia es una limitación y que todo conocimiento es una liberación'" (4).

\section{Aproximación al pensamiento bioético en América Latina}

- n 1996, Patrão Neves con- sideró que, por una serie de _ factores, para América Latina era muy difícil lograr una sistematización rigurosa y significativa de la Bioética. Entre estos factores están: su incursión relativamente tardía en la disciplina; gran diversidad y el diferente nivel de desarrollo entre los países; desequilibrios sociales; y acentuados desniveles de educación de la población, "que en su conjunto imponen discrepancias significativas en la sensibilidad de los temas fundamentales de la Bioética", temas que en su opinión se mantienen en común, pero que en su discusión se aprecia una mayor preocupación legalista y una marcada intención educativa dirigida a los profesionales de la salud, y en particular a los médicos, que lo que ocurre en América del Norte o en Europa.

Considera la autora que la perspectiva de reflexión Bioética en la región, sobre todo en los modelos de análisis empleados. Muestra una mayor proximidad con el pensamiento aglo-americano, sin embargo, "(...) el sentido crítico que va aumentando su expresión, incidiendo particularmente en el énfasis atribuido a algunas problemáticas en detrimento de otras, se aproxima más a una sensibilidad europea con su cultura latina y con valores católicos que tradicionalmente han influido en la formación del modo de ser y de sentir de los pueblos latinoamericanos" (5).

Para M. Kottow, la peculiaridad del pensamiento latinoamericano ha sido más intuida que empíricamente estudiada y falta que sea formulada con rigor, después de surgir tensionada entre la tutoría intelectual del principalismo y la intuición del lenguaje liberal, con predominio de la idea de la autonomía individual, que no se aviene con la tradición religiosa cultural y política de las sociedades mediterráneas e iberoamericanas. En su opinión: "El rechazo apriorístico del principalismo aparece precipitado e injustificado, produciendo un quiebre en el diálogo de la Bioética, que es pernicioso 
por destruir más de lo que aporta. Un modo más riguroso de abordar el problema consiste en adoptar la estrategia generalmente propuesta en la investigación filosófica: respetar el cuerpo de conocimientos vigentes y elaborar las necesarias modificaciones, y desde allí aceptar, pues, el principalismo como una base de análisis, fijar lo que pueda tener de universal y pesquisar en qué medida pueda ser elaborado, para luego adaptarlo a nuestra realidad cultural". Para este autor, si aceptamos el movimiento social de secularización y la emergencia del multiculturalismo en defensa de las minorías culturales, "será consecuente requerir de una Bioética latina que elabore una propuesta en la cual se identifique y represente la visión de un mundo mediterráneo y un tercer mundo americano, en respeto de sus diversidades étnicas y culturales, producto de la mezcla de razas y la amalgama de corrientes migratorias que caracterizan su historia" (6).

\section{Perspectivas para una caracterización Bioética}

a Bioética latinoamericana debe fundamentarse en premisas conceptuales que consoliden filosóficamente su autonomía y autenticidad.

Una de estas premisas es el concepto de bioetica global de V. W. Potter, que propicie "el desarrollo de una moral evolutiva (...), humilde, responsable y competente, dedicada hacia la supervivencia a largo plazo de la especie humana, (...) a la protección de la dignidad humana, (...) y a la presencia y el restablecimiento del ambiente saludable. Moral evolutiva que debería ser capaz de enfrentar la llamada 'imperfeccion fatal' de la evolución, o sea, el hecho de que la evolución favorece a corto plazo a los individuos altamente especializados y perfectamente adaptados a su medio ambiente, lo que puede resultar una fatalidad en el largo plazo (...) Por eso el medio cultural, construcción específica de la especie humana, debería balancear adecuadamente el instinto individual a corto plazo y las necesidades a largo plazo de las especies para una supervivencia aceptable, en contraste con la mera supervivencia de una sobrevida miserable" (7).

El concepto de Bioética profunda, que implica la idea revolucionaria de un estilo de vida llevadero y sostenible que pueda persistir en una forma aceptable hasta el cuatro milenio y más allá, en una población mundial aceptable de amplia diversidad y democrática con salud y justicia humana. Este necesario estilo de vida exigirá conocimiento ecológico y moralidad capaces, que puedan decir a las personas no solo lo que deben hacer para su propia supervivencia, sino lo que deben hacer para beneficio de las futuras generaciones (8). 
Una Bioética de tradición personalista, que hunde sus raíces en la razón misma del hombre y el corazón de su libertad: el hombre es persona porque es el único ser en el que la vida se hace capaz de reflexionar sobre sí misma, de autodeterminarse, con capacidad de captar y descubrir el sentido de las cosas y de dar sentido a sus expresiones y a su lenguaje consciente (9). Una concepción personalista que mantiene la primacía y la intangilidad de la persona humana, como valor supremo, fin y no medio, la que remite la persona al ser. "Solo a partir de este fundamento es posible construir una Bioética plenamente respetuosa con la dignidad última de la persona humana. Esta dignidad es la que exige el máximo respeto (...), en el terreno de la Bioética, desde el momento de la concepción al de la muerte natural" (10).

Una ética que no sea la del mandato y la obediencia, como nos señala Diego Gracia, "y tampoco la ética del derecho-deber de la modernidad, sino una ética distinta, que yo Ilamaría de la obligación, del compromiso, la responsabilidad". Ese tercer horizonte ético que proclama Gracia, de "una ética no basada ya en la ley natural o en la idea del deber-derecho, propios de la modernidad, sino en la idea de la obligación, entendiendo la obligación (...), de estar el ser humano constitutivamente obligado (...), estar ligado a otros hombres, ligado a la vida, a todos los ecosistemas, ligado a la naturaleza (...), a la sensibilidad (...), para con la naturaleza, siendo la naturaleza un a priori de mi propia autonomía y de la vida también..."(11).

Una Bioética "fuerte", como propone V. Garrafa para los países periféricos que defiende como moralmente justificable, entre otros aspectos: i)...la priorización de políticas y tomas de decisión que privilegien el mayor número posible de personas, incluso en perjuicio de ciertas situaciones individuales, con excepciones a ser discutidas; ii)...la búsqueda de soluciones alternativas viables y prácticas para los conflictos, que surjan del propio contexto de estudio. Esta propuesta, en opinión del autor, "propone una alianza liberal concreta con el lado históricamente mas frágil de la sociedad, incluyendo el reanálisis de diferentes dilemas, entre los cuales se destacan: autonomía versus justicia/equidad/universalidad; beneficios individuales versus beneficios colectivos; individualismo y omisión versus participación; compasión piadosa versus solidaridad; cambios superficiales y temporales versus transformaciones concretas y permanentes" (12).

Una Bioética intervencionista como visión propia de los bioeticistas de países periféricos para el abordaje de los problemas y conflictos que surgen de diferentes orígenes, y cuya magnitud y complejidad tienen que enfrentar para sus grupos sociales en desventaja y excluidos, en contraste con los problemas y conflictos que confrontan 
los bioeticistas de países centrales con grupos sociales favorecidos. Las respuestas a estos problemas, su interpretación y las decisiones o, por

\section{Conclusión}

J. Drane, al expresar sentirse sorprendido por la dimensión filosófica de los latinoamericanos, considera que es precisamente esa capacidad la que ha de resultar favorable para el desarrollo de una Bioética propia: "La sensibilidad humanística (...), la capacidad de amistad y una cultura muy rica son elementos que favorecen el desarrollo de una disciplina Bioética autóctona. El mismo idioma (de raíz latina) que le da conceptos y manera de pensar en común, la estructura política, las clases sociales,

\section{Biblografía}

Lolas, F. Impresiones sobre la Bioética en América Latina. Revista Latinoamericana de Bioética. Editorial Universidad Militar deNueva Granada, Bogotá. N ${ }^{\circ}$ 6, Enero 2004. pp: 28.

Salas, J.C. La posibilidad de una Bioética latinoamericana. Editorial

Boletín Biovínculo 8-9. FELAIBE. Enero-marzo, 1997.

Mainetti, J.A. Las perspectivas de la Bioética en América Latina y el Caribe. Cfr. 1er Congreso de Bioética, FELAIBE, Sao Paulo, oct.1995.

Gros, H. Latinoamérica y la Bioética. Boletín Informa. Programa lo menos, el esfuerzo para buscar soluciones favorables, no pueden ser las mismas (13).

una tradición religiosa similar y los mismos problemas con sus dilemas éticos ameritan aunar esfuerzos en la búsqueda de alternativas de solución de los mismos (...). Habrá que ver en la evolución de esa Bioética el rol de la familia, el énfasis en lo social, en la equidad, en la solidaridad y en la justicia". Y concluye recomendando: "Se deben evitar rivalidades y conflictos improductivos. Somos pocos en un mundo con muchos problemas. Paciencia, humildad y buena suerte" (14).

Regional Bioética OPS/OMS, No.12, Dic.1996. pp: 3.

Patrão, M. Fundamentación antropológica de la Bioética. Cuadernos de Bioética OPSD/OMS, No. 2, 1997. pp: 17-18.

Kottow, M. Esbozo multicultural del principalismo bioético. Cuadernos de Bioética OPS/OMS, No.2, 1996. pp: 32-39.

Potter, V.R. Global Bioethics, Building on the Leopold Legazo. Michigan State University Press. 1988.

Potter, V. R., Whitehouse, Peter J. Deep and Global Bioethics for a livable Third Millennium. The 
Scientist, Vol 12 \#1, January 5 , 1998. pp: 9.

Sgresccia, E. Manual de Bioética. Ed. Diana, Mexico , 1996. pp: 16-17.

León, F.J. Las ideas de la época contemporánea y sus aplicaciones ético-antropológicas. Memorias Congreso Internacional de Bioética, Universidad de La Sabana, Bogotá. Julio 1997. pp: 31-34.

Gracia, D. Pasado, presente y futuro de la etica. Memorias FELAI-
BE. Ed. CENALBE, Bogota, En. 1999. pp: 50-59.

Garrafa, V. Bioética fuerte. Cfr Tercer Congreso de Bioética FELAIBE, Panamá, Mayo 2000.

Garrafa, V. Intervention Bioethics. Bioethics Vol. 17 No 5-6, oct.2003, pp: 399-416.

Drane, J. Bioética Latinoamericana. Una visión critica. Cfr. Programa Regional Bioética OPS/OMS, Santiago, Chile, nov.1994. 